\title{
Evaluation of Spatial Imbalances in the Largest City: Ekaterinburg as a Case Study
}

\author{
Arina Suvorova* \\ Institute of Economics of the Ural Branch of the Russian Academy of Sciences, Ekaterinburg, Russian Federation \\ ${ }^{*}$ Corresponding author.Email: suvorova.av@uiec.ru
}

\begin{abstract}
Inequality is a major obstacle to implementation of the concept of sustainable development. The study is devoted to consideration of one of the aspects of this important problem - inter-territorial imbalances, which can reduce the efficiency of using the potential of individual territories and the entire system as a whole. The purpose of the paper is to assess the degree of homogeneity of the space of a major city, revealing the scale of inequality between its elements. The paper analyzed data on location of trade facilities, public catering and consumer services throughout the city; the methodological basis of the study was made up of indicators characterizing the degree of heterogeneity of parameters of development of objects (coefficients of variation, asymmetry, Hall-Tydeman index and Gini coefficient). Calculations carried out using statistical information about the city of Yekaterinburg and its territorial units have shown that the choice of basic units of analysis has a significant effect on the "sensitivity" of the assessment. Focusing on data on development of large territorial units (administrative districts), characterized by the high level of heterogeneity, does not allow to draw reasonable conclusions about the scale of intracity imbalances: a more accurate assessment can be made by analyzing microdistricts. It has been determined that the space of functioning of the considered places of attraction of the population cannot be called homogeneous (although the scale of inequality is not critical), and the levels of inequality in the inter-territorial distribution of objects of different types differ insignificantly. It is shown that the management of spatial transformations is a necessary condition for ensuring the balanced development of the territorial system (even at the local level).
\end{abstract}

Keywords: spatial homogeneity, elimination of inequality, spatial development, largest city.

\section{INTRODUCTION}

The concept of sustainable development, the main provisions of which began to take shape more than 50 years ago [1] and today does not lose its relevance: its ideas are in demand when looking for answers to the challenges of the present, and the importance of a reasonable combination of economic, social and environmental priorities is becoming the main topic not only a number of scientific papers [2, 3], but also documents documenting the policy of states and their associations. However, the concept presupposes not only the harmonization of economic growth, social justice and responsible attitude to the environment [4] it pays much attention to solving those problems that threaten the balanced and dynamic development of territorial systems.

These include the issues of eliminating inequality (in all its manifestations) and ensuring equal access to resources for further transformation. In the context of the transformation of territorial systems, inequality can be talked about through the prism of assessing the peculiarities of location of subjects and objects: the specificity of their localization is a powerful factor of convergence (separation) of the parameters of the socioeconomic development of territorial units [5], acting as a condition for transformation of the scale of differences.

It may seem that for local territorial systems (cities, agglomerations), the problem of disproportions in the location of assets (for example, elements of social infrastructure) cannot be called significant: the relatively small size of such systems allows each resident to quickly get to any object, regardless of which area or part of the city it is located. However, it is obvious that the parameters of such accessibility do not always correspond to the daily needs of the population: the services provided by a number of objects (educational institutions, trade organizations, sports grounds, etc.) are used by residents on a regular basis. In 
those urban areas (districts, micro-districts) that are not provided with such places of attraction, not the most favorable conditions for life are formed: their residents are forced to bear additional costs (both cost and time) when receiving services. As a result, the environmental characteristics of such territories are inferior to the parameters of other areas, making them less attractive for both residents and businesses, as well as contributing to their "dropout" from the socio-economic space of the city (which, in turn, becomes more fragmented, scattered). Therefore, the features of the spatial organization of the system of objects demanded by residents directly affect the possibilities of transforming individual territorial units, the sustainability of the development of the entire urban system, and the heterogeneity of the urban space (determined by the parameters of the provision of its individual elements with heterogeneous resources) can be a very reliable indicator of presence of an inequality problem.

The study is devoted to assessing the degree of homogeneity of the space of the largest city and focuses on determining the features of the localization of objects in demand by its residents.

\section{MATERIALS AND METHODS}

To carry out the study, data showing the specifics of the location of trade, catering and consumer services in the space of Yekaterinburg - a large city (the population at the beginning of 2021 exceeds 1.5 million people), which is at the same time a fairly compact settlement, were used. These objects are closely related to attractiveness of individual locations, acting, on the one hand, as a factor, on the other hand, as an indicator of interest in them on the part of business and the population. In turn, the choice of Yekaterinburg as a testing ground is due to the attention shown in the city to monitoring the situation that is developing in its individual territories: in 2019-2020 in the process of developing strategies for the socio-economic development of 7 administrative districts, data was collected on the features of the functioning of 57 microdistricts - planning districts (large structural units allocated in the interests of more balanced territorial planning and including zones that differ in functionality, capable of providing conditions for work, life and recreation of the population).

All the statistical and graphic data necessary for analysis (both in the district and in the microdistrict scale) are presented on the official portal of the city (https:// екатеринбург.рф). Wherein, from the complete list of micro-districts, the largest were selected (the number of inhabitants of which exceeds 5 thousand people). There are 41 such microdistricts. Exclusion from the analysis of sparsely populated areas is associated with the need to get rid of objects, the scale of which does not allow them to have a significant impact on the estimated sample, while introducing "statistical noise".

Due to the considerable interest shown by the scientific community in measuring the scale of intracity disparities, the methodological tools for such an analysis are quite diverse: cartographic analysis [6], sociological surveys [7], and spatial modeling [8,9] are widely used. However, the availability of statistical data characterizing the features of development of individual territorial units makes it possible to use simple, but at the same time extremely indicative ways of assessing the scale of spatial differentiation. These include the coefficients of variation and asymmetry, which are often used in statistics to determine the degree of heterogeneity of a set of data, as well as special indicators that allow one to assess the extent of inequality in the distribution of objects in space, the parameters of their concentration (Gini coefficient, HallTidman index).

The coefficient of variation characterizes the degree of variability of the indicator in relation to its average value, representing a standard measure of the variance of the probability distribution [10]. The skewness coefficient depends on the features of the distribution of the random variable, determining the measure of the discrepancy between the actual values and the normal distribution [11]. The Gini coefficient [12] is traditionally used to characterize income inequality (it allows to determine the degree of deviation of the actual distribution of income among social groups from their theoretically possible uniform distribution), but it can also be used to assess the specifics of spatial development [13]. The Hall-Tydeman index [14] is a rank concentration index and serves to characterize the characteristics of market development (however, it is also applicable for territorial analysis [15]).

\section{RESULTS AND DISCUSSION}

In Soviet times, Yekaterinburg was a large industrial center, the share of industrial production in the economy of which exceeded $90 \%$. However, the reforms of the 1990s and the activation in the 2000s of the processes of strategic management of the urban economy led to the rapid growth of the service economy: trade, the entertainment sector, tourism and public catering were developing. The change in the city's space at that time was largely determined by the ongoing restructuring of the economy: large shopping centers, large-scale complexes providing a wide range of personal services, catering establishments, often localized on one site, began to appear in the territory of Yekaterinburg. At present, the sector of the service economy does not show such dynamics as in the initial stages of development, but its scale remains very significant. This allows to assume the presence of imbalances of a different nature (including inter-territorial ones), which 
are often inherent in any complex system, consisting of a significant number of elements.

However, the analysis of the localization features of objects that are places of attracting residents, carried out in the context of data on the administrative districts of Yekaterinburg, does not allow to conclude that there are significant differences between the territories (Table 1).

The coefficients of variation for each of the considered parameters, although they exceed the standard value (0.33), indicating the homogeneity of the analyzed data sample, differ from it very insignificantly. The values of the asymmetry coefficient diverged from the standard value (0.5) to a greater extent, but such a deviation can hardly be called significant, which, in general, confirms the thesis about absence of significant disproportions in the characteristics of regions. A similar conclusion can be drawn from the analysis of the Gini coefficient values (they are closer to 0 , not 1 ). The Hall-Tideman index, which assesses the degree of concentration of objects - the level of their concentration in one or several centers - also indicates a high level of territorial homogeneity (there are no pronounced leaders that are significantly ahead of other areas in terms of the provision of retail, service areas, and catering facilities).

Wherein, the degree of heterogeneity in the location of the analyzed objects is slightly higher than the degree of heterogeneity in the settlement of residents in the urban space (this is especially clearly demonstrated by the parameters of data asymmetry), which allows to draw conclusions about the presence of imbalances (although not very significant) between the potential demand for this kind of objects and their offer.

However, it shall be noted that it is somewhat premature to draw conclusions about absence of significant disparities between individual territories of the city in terms of the parameters under consideration on the basis of the calculations performed. Use of the administrative districts of the city as the basic elements of the analysis may lead to a misinterpretation of the specifics of the processes taking place in the territory. This is due to the fact that each such area occupies a very significant area, accumulating within its borders many territorial units that differ from each other in a wide range of development parameters. In the case of
Yekaterinburg, an important circumstance is also the nature of the localization of districts: in the administrative context, the city has a sectoral structure (Figure 1), which determines the presence in each considered zone of both peripheral territories, the values of provision with places of attraction of residents, which traditionally lag behind the average annual level, and central ones (which, on the contrary, are characterized by a high concentration of such objects).

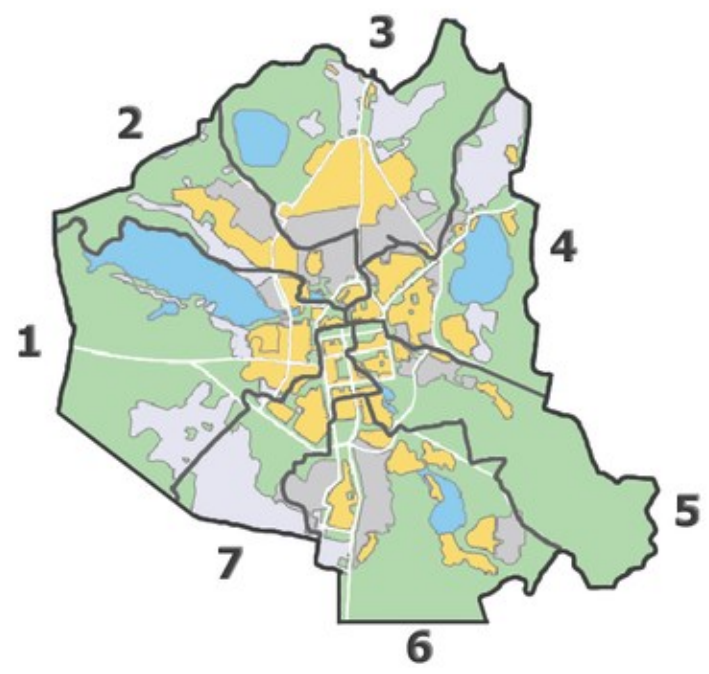

Figure 1 Administrative Division of Yekaterinburg

Microdistricts are more suitable sites for such a study: they have internal homogeneity, being at the same time complex systems (by combining territories differing in their functionality), and the peculiarities of their allocation in the city space allow a deeper analysis of urban space due to its more "fractional" division (Figure 2).

Table 1. The parameters of the homogeneity of the space of functioning the trade facilities, catering and consumer services (in the context of administrative districts)

\begin{tabular}{|c|c|c|c|c|}
\hline & $\begin{array}{l}\text { Variation } \\
\text { coefficient }\end{array}$ & $\begin{array}{l}\text { Asymmetry } \\
\text { coefficient }\end{array}$ & $\begin{array}{l}\text { Gini } \\
\text { coefficient } \\
\end{array}$ & $\begin{array}{l}\text { Hall-Tydeman } \\
\text { Index } \\
\end{array}$ \\
\hline Provision of the population with retail space & 0.51 & 0.98 & 0.213 & 0.182 \\
\hline $\begin{array}{l}\text { Provision of the population with places in public } \\
\text { catering enterprises }\end{array}$ & 0.47 & 1.28 & 0.138 & 0.166 \\
\hline \begin{tabular}{|l}
$\begin{array}{l}\text { Provision of premises for consumer } \\
\text { enterprises }\end{array}$ \\
\end{tabular} & 0.38 & 0.93 & 0.135 & 0.166 \\
\hline Population (for reference) & 0.27 & 0.28 & 0.136 & 0.166 \\
\hline
\end{tabular}




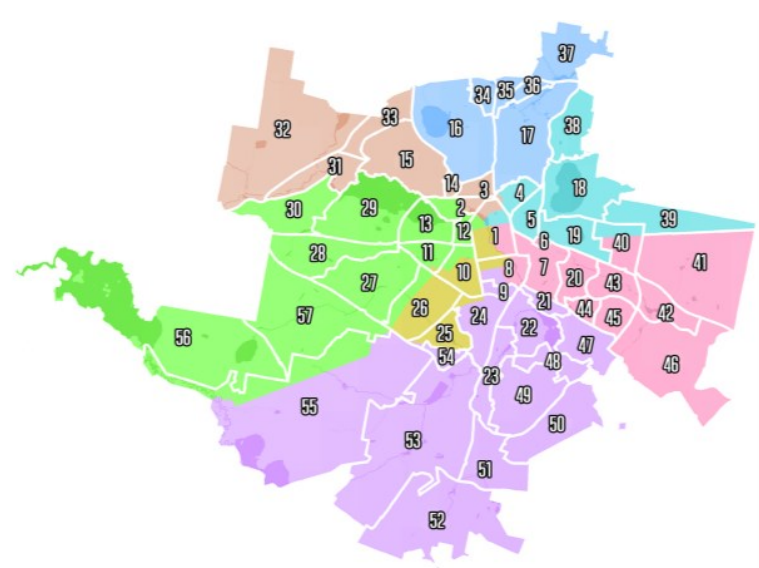

Figure 2 Microdistricts identified in the space of Yekaterinburg

The results of the analysis of the homogeneity of the space of functioning the trade facilities, public catering and consumer services, carried out in the context of microdistricts, indicate that the environment of Yekaterinburg is still not geographically balanced (Table 2).

Microdistricts differ from each other to a much greater extent than administrative districts: the coefficients of variation and asymmetry exceed the standard values not 2-3 times, but 5-6 times. The values of the Gini coefficient, although they are not close to 1 , clearly gravitate towards it (the only exception is the value of the coefficient calculated for the parameter of provision of residents with areas for consumer services, but it is also more likely to be in the middle zone, and not in the zone tending to zero).

The values of the Hall-Tideman index look somewhat paradoxical: their value decreased with a change in the level of analyzed data (and did not increase as in the case of other indicators), which indicates an extremely low level of concentration of objects (the closer the value of the index to 1 , the more significant the level of their concentration in one or more centers). This is due to the fact that among the micro-districts there are a lot of such territories that accumulate on their areas a large number of gravity points of residents.

It is also interesting to compare the degree of heterogeneity in the distribution of objects of different types over the territory of the city: catering enterprises show a tendency towards the least balanced location, while consumer services, on the contrary, are located in the space most evenly. Wherein, the noted difference can hardly be called significant: the values of the homogeneity parameters are very close to each other.

\section{CONCLUSIONS}

Study has shown that space of functioning the objects of trade, catering and consumer services regarding the compact territorial system (within the boundaries of one city) is not homogeneous. The scale of inequality cannot be called critical (all the objects considered are not localized at one point in space - in one zone), however, there are imbalances in the level of provision of individual territorial units with places that serve as points of attraction for the population; there are both clear leaders and obvious outsiders. Moreover, the fact that the degree of inequality in the inter-territorial distribution of objects of different types is approximately the same, testifies to the objectivity of the existence of intracity disproportions.

However, is this form of inequality an obstacle to the transformation of a city into a sustainable socioeconomic complex? Even a small territorial system (an example of which is a city) objectively cannot be built on the principles of absolute uniformity in the development of its individual elements; in addition, the effectiveness of any management decisions is questionable (for example, on the part of city authorities) associated with the artificial "introduction" of objects (development resources) into the space of those territories where there are not enough such objects. On the other hand, ignoring the tasks associated with improving the balance of urban spaces in the future only leads to an increase in inter-territorial fragmentation, a decrease in the efficiency of using the potential of the territory and exacerbation of existing problems.

Therefore, the issues of managing space transformations (including in the interests of ensuring balanced development of the separate territories, which presupposes the prevention of excessive inequality between them) need a solution, but the implemented policy requires fine tuning. The actions taken should not be subordinated to the pursuit of the achievement of security standards - formation of a comfortable, open

Table 2. The parameters of the homogeneity of the space of functioning the trade facilities, catering and consumer services (in the context of microdistricts).

\begin{tabular}{|l|c|c|c|c|}
\hline & $\begin{array}{c}\text { Variation } \\
\text { coefficient }\end{array}$ & $\begin{array}{c}\text { Asymmetry } \\
\text { coefficient }\end{array}$ & $\begin{array}{c}\text { Gini } \\
\text { coefficient }\end{array}$ & $\begin{array}{c}\text { Hall-Tydeman } \\
\text { Index }\end{array}$ \\
\hline $\begin{array}{l}\text { Provision of the population with retail space } \\
\begin{array}{l}\text { Provision of the population with places in public } \\
\text { catering enterprises }\end{array}\end{array} \quad 1.44$ & 2.74 & 0.544 & 0.054 \\
\hline $\begin{array}{l}\text { Provision of premises for consumer services } \\
\text { enterprises }\end{array}$ & 1.04 & 3.22 & 0.608 & 0.064 \\
\hline
\end{tabular}


environment, attractive for residents and guests of the city, deserves the utmost attention.

In turn, the need for a competent influence on the spatial characteristics of the city predetermines the importance of monitoring the processes that form these characteristics. Wherein, as the study showed, within the implementation of spatial analysis, not only the specifics of the methodological tools used (indicators selected for analysis, data processing algorithms, and etc.) are important, but also the features of those territories that act as basic units of analysis.

Obviously, the performed analysis touched only a small part of the complex problem associated with the search for parameters for the optimal organization of space. Wherein, the study made it possible to draw a number of conclusions that develop the results of numerous studies devoted to assessing the parameters of achieving sustainable development benchmarks, and may be of interest both to representatives of the scientific community analyzing various aspects of this topic, and to specialists who manage territorial systems of different levels.

\section{ACKNOWLEDGMENTS}

This work is supported by the Russian Science Foundation under grant 20-78-00067.

\section{REFERENCES}

[1] D. H. Meadows, D. L. Meadows, J. Randers, W. W. Behrens, The Limits to Growth: A Report for the Club of Rome's Project on the Predicament of Mankind, Universe book (1972).

[2] Y. Vertakova, V. Plotnikov, Problems of Sustainable Development Worldwide and Public Policies for Green Economy, in: Economic AnnalsXXI 166(7-8), (2017), pp. 4-10. https://doi.org/10.21003/ea.V166-01.

[3] S. Weiland, T. Hickmann, M. Lederer, J. Marquardt, S. Schwindenhammer, The 2030 Agenda for Sustainable Development: Transformative Change through Sustainable Development Goals? In: Politics and Governance, 9, (2021), 90-95. https://doi.org/10.17645/pag.v9i1.4191.

[4] C. A. Poveda, The Theory of Dimensional Balance of Needs, in: International Journal of Sustainable Development \& World Ecology, 24(2), (2017), pp. 97-119.

https://doi.org/10.1080/13504509.2016.1201019.

[5] S. J. Rey, M. V. Janikas, Regional convergence, inequality, and space, in: Journal of Economic Geography, 5(2), (2005), 155-176. https://doi.org/10.1093/jnlecg/lbh044.
[6] Q. Chen, M. Du, Q. Cheng, C. Jing, Quantitative Evaluation of Spatial Differentiation for Public Open Spaces in Urban Built-Up Areas by Assessing SDG 11.7: A Case of Deqing County, in: ISPRS International Journal of GeoInformation, 9(10)

(2020). https://doi.org/10.3390/ijgi9100575.

[7] N. McClintock, D. Mahmoudi, M. Simpson, J. P. Santos, Socio-spatial differentiation in the Sustainable City: A mixed-methods assessment of Landscape and Urban Planning, 148, (2016), pp. 116. https://doi.org/10.1016/j.landurbplan.2015.12.008.

[8] E. Talen, The Social Equity of Urban Service Distribution: An Exploration of Park Access in Pueblo, Colorado, and Macon, Georgia, in: Urban Geography, 18(6), (1997), pp. 521-541. https://doi.org/10.2747/0272-3638.18.6.521.

[9] X. Yang, F. Niu, D. Sun, Evaluation of Urban Spatial Equality Based on Accessibility to Economic Activities: Beijing as a Case Study, in: Complexity https://doi.org/10.1155/2020/4560146.

(2020).

[10] A. Bedeian, K. Mossholder, On the Use of the Coefficient of Variation as a Measure of Diversity. Organizational Research Methods, 3, (2000), pp. 285-297. https://doi.org/10.1177/109442810033005.

[11] D. P. Doane, L. E. Seward, Measuring Skewness: A Forgotten Statistic? In: Journal of Statistics Education, $\quad 19(2)$ (2011). http://jse.amstat.org/v19n2/doane.pdf.

[12] L. Ceriani, P. Verme, The Origins of the Gini Index: Extracts from Variabilità e Mutabilità (1912) by Corrado Gini, in: The Journal of Economic Inequality, 10, (2012), pp. 421-443. https://doi.org/10.1007/s10888-011-9188-x.

[13] K. -M. Nam, Is Spatial Distribution of China's Population Excessively Unequal? A Cross-country Comparison, in: Annals of Regional Science, 59(2), (2017), pp. 453-474. https://doi.org/10.1007/s00168-017-0839-0

[14] M. Hall, N. Tideman, Measures of Concentration, in: Journal of the American Statistical Association, 62, (1967), pp. 162-168.

[15] A. I. Kostyaev, Rural Areas of Russia's North-west Borderland: Problems and Development Paths, in: Baltic Region, 11(4), (2019), pp. 93-113. https://doi.org/10.5922/2079-8555-2019-4-6. 